\title{
Dimensions of Intercompany Cooperation in the Construction Industry and their Relations to Performance of SMEs
}

\author{
Anna Michna ${ }^{1}$, Roman Kmieciak ${ }^{2}$, Agnieszka Czerwinska-Lubszczyk ${ }^{3}$ \\ ${ }^{1,2}$ Silesian University of Technology \\ 26 Roosevelta st., 41-800 Zabrze, Poland \\ E-mail.anna.michna@polsl.pl; roman.kmieciak@polsl.pl \\ ${ }^{3}$ University of Bielsko-Biala \\ 2 Willowa Str., 43-309 Bielsko-Biala, Poland \\ E-mail.aczerwinska@ath.bielsko.pl
}

cross $^{\text {ref }}$ http://dx.doi.org/10.5755/j01.ee.31.2.21212

\begin{abstract}
Cooperation between companies is widely believed to have positive impact on their performance. However, there is insufficient empirical research on relationships between these constructs in small and medium-sized enterprises (SMEs) in the construction industry. Moreover, cooperation is a complex and multidimensional phenomenon, and it is interesting how different dimensions of cooperation may influence the company's performance. To bridge the research gap, the following study is performed, which: (1) identifies dimensions of intercompany cooperation, and (2) examines the relationships between dimensions of cooperation and the performance of SMEs. Eight dimensions of cooperation were identified, based on 125 observations obtained from Polish construction SMEs. It appears that a company's openness to cooperation is dependent on the company's maturity and the competition between partners. Surprisingly, no significant connection was observed between the cooperation, financial performance and the change in the number of employees. It is considered that the cooperation in the construction industry, although not related to financial performance in a significant or direct way, is common and may be essential for the survival of SMEs.
\end{abstract}

Keywords: Cooperation; Company Performance; Construction Industry; SMEs; Poland.

\section{Introduction}

Intercompany cooperation is widely perceived as an opportunity to improve company's performance. Cooperation can be often perceived as a security mechanism that reduces risk and mitigates external threats (Beuve \& Saussier, 2011). Moreover, cooperation allows to gain access to resources of other organizations and to achieve goals that would be much more difficult or even impossible to achieve by the company on its own (Maldonado-Guzman et al., 2012). Many researchers connect cooperation with cost reduction, entering new markets, transfer of knowledge between partners and improvement of the company's innovativeness (Fink et al., 2010; Maldonado-Guzman et al., 2012).

Intercompany cooperation is particularly important in the construction industry, where large and complex projects are often carried out, requiring the participation of many entities. Thus, construction companies are forced to enter into relationships with the main contractor, subcontractors, suppliers of building materials, designers and engineers (Welling \& Kamann, 2001). The need to build cooperative relations is especially important to small and medium enterprises (SMEs), which, due to limited resources, are not able to implement large projects on their own, but often play an important role as subcontractors of large enterprises. However, the willingness to cooperate with other enterprises may be hindered by various factors, such as lack of trust in partners (European Commission, 2015) or fear of being dominated by larger companies from the industry (Rezgui \& Miles, 2010).

Cooperation should be beneficial to enterprises. The literature on the subject generally confirms the advantages of such relationship (Lamprinopoulou \& Tregear, 2011; Fink \& Harms, 2012). However, the connection between the cooperation and SME's performance in the construction industry has not been sufficiently investigated. It is interesting to examine whether the cooperation in the construction industry can improve the financial performance of an SME. However, it should be noted that cooperation is a complex and multidimensional phenomenon, and the literature indicates various factors associated with it, i.e. trust (Rese \& Baier, 2011), formalization and mutual influence (Schmoltzi \& Wallenburg, 2012), motives and barriers of cooperation (Danik \& Lewandowska, 2013), or competition between collaborative companies (Zhang et al., 2010). Therefore, the interesting and current problem can be formed into two points: what dimensions of intercompany cooperation can be distinguished and how these dimensions affect the performance of an SME.

Thus, the main purpose of this paper is to examine the connection between intercompany cooperation and company performance in case of SMEs operating in the construction industry. Consequently, the following research questions were stated:

RQ1. What are the dimensions of cooperation in the construction industry? 
RQ2. What affects the openness to cooperation of SMEs in the construction industry?

RQ3. What impact does the cooperation have on company's performance in case of a construction SME?

To achieve the goal of this study, and answer the research questions, a quantitative research analysis was conducted, based on 125 observations obtained from Polish construction SMEs.

\section{Theoretical Background}

\section{Characteristics of Construction Industry}

The construction industry is perceived as one of the most dynamic and complex industries. It is often emphasized, that the construction industry is strongly related to the economic situation, and fluctuations in economic markets have a clear impact on the number and size of ongoing construction projects (Raiden \& Dainty, 2006; Organisation for Economic Co-Operation and Development, 2008). Furthermore, the industry is characterized by the fact that the end product is largely unique and cannot be transported, which must be assembled in its intended location (Cegarra-Navarro \& Sanchez-Polo, 2011). Due to that, the resources used (equipment, vehicles, materials, and labour) need to be mobile, in order to move to different project locations (Sarkar et al., 2001). The implementation of construction projects is usually seasonal, weather-dependent, time-consuming (long-lasting), requires the involvement of significant capital and must comply with numerous laws, regulations and standards (Michna et al., 2015). The high complexity of construction projects requires cooperation not only with clients, designers and suppliers, but often requires also close cooperation with other construction companies. Moreover, due to the sequentiality and interdependence of works, contractors are mutually dependent. Cooperation and subcontracting in the construction industry is seen as a normal way of doing business (Organisation for Economic CoOperation and Development, 2008), although relationships in this industry might be short-lived, created for the needs of one particular project (Havenvid et al., 2017).

Even large companies need to involve smaller, specialized contractors to realize certain aspects of their construction projects (Organisation for Economic CoOperation and Development, 2008). As stated by Rezgui and Miles (2010), SMEs in the construction industry are often dependent on large industry players, which means that they have little opportunity to add value. SMEs are involved in both off-site manufacturing, including design and procurement, as well as on-site production assembly and supporting services (Rezgui \& Miles, 2010). Cooperation with other enterprises is fostered by high flexibility of SMEs (Krajnakova et al., 2015; Michna, 2018), which allows them to react to the changes in their environment faster than in case of large enterprises. Moreover, thanks to informal relationships, they can easily enter into cooperative relations. The attitude of an SME owner/manager plays a decisive role. It is their personality, education, competences, motivation, entrepreneurial orientation, as well as formal and informal contacts, that determine the development of the company (Kozan et al., 2012; Arthur-Aidoo et al.,
2016), including the establishment of cooperation with domestic and foreign organizations.

\section{Dimensions of Cooperation}

Literature review shows a great interest of researchers in the subject of inter-organizational relations, such as collaboration, partnering and cooperation (Sepehri \& Fayazbakhsh, 2011; Kamnungwut \& Guy, 2012; Mantena \& Saha, 2012; Yitmen, 2013; Cabras \& Pearson, 2014). Cooperation can be defined as "the process in which companies pursue their own goals, and thus retain autonomy, while, at the same time, orienting their actions towards joint outcomes" (Doucette \& Wiederholdt, 1997, p. 976), "relationship between independent companies or associates, through which they combine their efforts and resources in a value-creation process" (De la Maza-y-Aramburu et al., 2012, p. 476), or "joint pursuit of agreed-on goal(s), in a manner corresponding to a shared understanding about contributions and payoffs" (Gulati et al., 2012, p. 533). Hence, the concept of cooperation includes such aspects as multi-entity character, the importance of pooling resources between cooperating organizations and focusing on achieving a common goal, which might be unachievable by organizations operating independently. Furthermore, cooperation can be horizontal or vertical, bilateral or multilateral, productive or innovative, informal or formal (Filho et al., 2015), but parties retain autonomy.

Important determinant of cooperation is interorganizational trust, which can be defined as one organization's expectation, that the other organization "(1) can be relied on to fulfil obligations, (2) will behave in a predictable manner, and (3) will act and negotiate fairly when the possibility of opportunism is present" (Zaheer et al., 1998, p. 143). Trust can also be viewed as an organization's confidence that the partner will not exploit its vulnerabilities (Sengun \& Wasti, 2011). Trust between partners increases the willingness to share knowledge and other resources, including advanced technology (Chai \& Yang, 2011; Rese \& Baier, 2011), which is particularly important for smaller enterprises. Relations based on trust facilitate dealing with conflicts (Chrupala-Pniak et al., 2017) and increase the propensity of partners to adapt to each other (Yong Koh \& Rowlinson, 2012). What is more, trust allows to limit the need for formal contracts, which are costly to write, control and enforce. This way, transaction costs incurred in inter-organizational cooperation can be reduced (Sengun \& Wasti, 2011). Empirical research confirms positive relationship between trust and cooperation (Rese \& Baier, 2011; Sengun \& Wasti, 2011; Yong Koh \& Rowlinson, 2012).

One of the key elements of inter-organizational cooperation, which reduces uncertainty, is formalization, which involves formal and mutually binding agreements, which specify e.g. detailed tasks, responsibilities, activities, schedules and operating procedures within the cooperation (Murray \& Kotabe, 2005). Formalization is expected to provide transparency of relationship behaviour, as well as support the stability and efficiency of cooperation (Schmoltzi \& Wallenburg, 2012). However, empirical research showed that the impact of formalization on cooperation is ambiguous (Beuve \& Saussier, 2011). 
Researchers indicate that cooperation cannot be subject only to formal regulations, and formal agreements cannot take into account all possible aspects and random events. Therefore, formal control within inter-organizational cooperation may be completed or even substituted by mutual influence (Schmoltzi \& Wallenburg, 2012). Mutual influence draws on social exchange theory and refers to the ability of each cooperative organization to influence the other. It is manifested in personal interactions, open communication and direct discussion of problems (Schmoltzi \& Wallenburg, 2012, p. 59). Mutual influence has a positive effect on learning and transfer of knowledge between partners (Muthusamy \& White 2005), cooperation commitment (Schmoltzi \& Wallenburg, 2012), performance and propensity of a partner to continue the cooperation (Muthusamy et al., 2007).

A part of social interactions is commitment to the relationship. It is defined as "an enduring desire to maintain a valued relationship" (Moorman et al., 1992, p. 316). Cooperation commitment results from the expected benefits of cooperation. It is associated with loyalty of the allied partners, willingness to use one's own resources and to make sacrifices to help partners (Perry et al., 2004). The partner engaging their own resources expects the same from the partners. Mutual exchange of resources strengthens the motivation for cooperation. On the other hand, the lack of mutuality may lead to a termination of cooperation. Prior empirical research indicated a positive impact of cooperation commitment on the stability of a relationship (Yang et al., 2008), cooperation effectiveness (Perry et al., 2004; Schmoltzi \& Wallenburg, 2012) and profitability (Holm et al., 1996).

As Rese and Baier (2011) stated, other important factors for an efficient cooperation are: compatibility of the network partners and their ability to cooperate. Partners' compatibility means that individual goals of the network partners are in line with the superordinate goal of the network. It is also manifested in various strategic and organizational aspects, such as financial issues, quality specifications, schedules and performance evaluation (Rese $\&$ Baier, 2011). On the other hand, the ability to cooperate depends on whether the partners are equipped with sufficient human, IT and financial resources, good communication behaviour and adequate bureaucratic structures.

The traditional approach to inter-organizational relationships assumes that relationships are based on either competition or cooperation. However, the current market situation forces companies, including construction companies, to undertake both competitive and cooperative activities at the same time (Walley, 2007). It is claimed, that competition cannot be avoided in cooperation relationships, and therefore alliances should be perceived as a mix of cooperation and competition (Zhang et al., 2010). Empirical research confirmed that competition and cooperation coexist in intercompany alliances, and both factors are positively related to knowledge acquisition (Zhang et al., 2010).

Each of the cooperating parties - designer, investor, contractor or subcontractor - significantly influences the success of the construction project. For example, errors in the technical documentation committed by the designers require a correction, which delays the implementation of the project. Moreover, delays can also be caused by low efficiency or the lack of competence of subcontractors' workforce. Therefore, business partner attributes might be crucial for successful cooperation in the construction industry. Survey conducted among Lithuanian companies (Lydeka \& Adomavicius, 2007) suggests that potential partners are selected according to the following criteria: trustworthiness/dependability, similarity of goals and interests, financial strength and pragmatic outlook to business. In turn, research conducted among French companies confirms that cooperation is enhanced by a partner's reputation (Beuve \& Saussier, 2011). Reputation "can be a substitute for costly mechanisms, that verify the intentions and monitor the actions of business partners" (Beuve \& Saussier, 2011, p. 816). Moreover, a relationship with highly-regarded companies may be very beneficial for a young company. It increases the entrepreneurial credibility and gives reputation, sending a signal to the market that such new company is a viable partner (Lechner et al., 2006).

Cooperation can take place in certain areas of the company's activity, such as: production, marketing, research and development, sales. As Danik and Lewandowska (2013) remarked, motives and barriers of cooperation in these areas might be different. Although there might be various motivates for cooperation, the main one is usually to improve strategic position of companies (Danik \& Lewandowska, 2013). This is done through providing resources from other companies that enable partners to share costs and risks (Arranz \& Fdez de Arroyabe, 2008; Fernandez-Ardevol \& Masllorens 2011). Cooperative companies have greater opportunities to develop, identify market niches, access export markets, and conduct personnel policy (Racela \& Thoumrungroje, 2014). Moreover, benefits from intercompany cooperation also include gaining access to financial capital, improved reputation, capacity for rapid learning, transfer of knowledge and faster development of innovation (Arranz \& Fdez de Arroyabe, 2008). Those benefits are particularly important for SMEs, which usually have limited knowledge, financial and human resources (Michna et al., 2017; Kmieciak \& Michna, 2018). Cooperation allows SMEs in the construction industry to expand their offer with services that they are unable to provide by themselves, due to SMEs' size and lack of sufficient resources.

On the other hand, some factors can hamper intercompany cooperation. Researchers identify such major problems, in terms of cooperation, as: failing to follow through with commitments, inability to find compromises, lack of initiative and lack of coordination with alliance members (Lydeka \& Adomavicius, 2007). Cooperation between construction companies requires the activity of employees at various levels (from managers to manual workers), which requires devoting additional time to meetings, negotiations or trainings. Lack of managerial/staff time and resources within the companies is found as one of the main barriers to the development of intercompany networks (Huggins, 1998). Moreover, sometimes companies are not aware of the benefits of networking (Huggins, 1998). An important barrier for cooperating companies is also the lack of agreement on profit-sharing modes (Sung-Lin \& Min-Ren, 2011). In the case of 
cooperation with foreign companies, such additional barriers are indicated as: differences in mentality, corporate culture and managerial style between business partners, different languages, and informational deficits with regard to potential (new) partner companies (Leick, 2011). According to research conducted in Poland, most important barriers of cooperation in the Polish engineering industry involve: negative cooperation experience, lack of complete trust and legal barriers (Danik \& Lewandowska, 2013).

To conclude, various factors can affect interorganizational cooperation, including trust, formalization, mutual influence, commitment and cooperation effectiveness, compatibility of the network partners, ability to cooperate, competition between partners, desired attributes of a business partner, areas of cooperation, motivation and barriers of cooperation.

\section{The Relationship between Cooperation and Company Performance}

Although intercompany cooperation is undertaken for various reasons, for example to access international markets or to share knowledge in cooperative innovation (Fink et al., 2010), it is expected that it will have a positive effect on company performance. The literature review on the impact of cooperation on performance of construction SMEs was carried out in two areas: the impact of cooperation on performance of SMEs and the impact of cooperation on performance of construction companies. This is due to the fact that there are no research results regarding the impact of cooperation on performance of construction SMEs.

Generally, the literature confirms that SMEs have significant benefits from cooperation. Research indicates that intercompany cooperation positively affects reduction of purchase costs, innovation, and financial performance (Maldonado-Guzman et al., 2012), business performance (Fink et al., 2010; Fink \& Harms, 2012), marketing performance (Lamprinopoulou \& Tregear, 2011), and innovation performance (Zeng et al., 2010; Lee et al., 2015). On the contrary, De la Maza-y-Aramburu et al. (2012) proved that SMEs which are members of cluster initiatives do not innovate more than non-associated companies. Hoetoro (2014) surprisingly found out that forward linkage negatively affected worker's productivity in micro and small enterprises operating in clusters. Moreover, Park et al. (2010) claimed that subcontracting does not have a statistically significant effect on company's growth.

When it comes to construction companies, empirical research on the relationship between cooperation and company performance is deficient. Oliver (1997) emphasized that quality of an organization's relationship with its task environment (developers, subcontractors, suppliers, and banks) positively affects the profitability and productivity. More recently, Lin \& Ho (2013) stated that, in the construction industry, jointly managed joint-ventures perform slightly better than separately managed ones. Nevertheless, there is a lack of research on SMEs in this field. On the basis of the above discussion, the following hypothesis is stated:

Hypothesis 1. The cooperation between SMEs in the construction industry is positively related to company's performance.

\section{Method}

\section{Sample and Procedure}

The research was conducted among small and mediumsized construction companies in the Upper Silesia Region of Poland. The data was collected from December 2014 to April 2015. The survey questionnaire was addressed to owners and managers of SMEs from the construction industry. It was assumed that such group of respondents has the best knowledge related to intercompany cooperation and company performance. Initially, the questionnaire was sent via e-mail. However, due to the low effectiveness of this method, the paper version of the questionnaire was delivered to the respondents. A total of 365 questionnaires were distributed. Finally, 98 questionnaires were collected, 96 of which were qualified for further research.

In the research sample, there was not a single enterprise that would declare a lack of inter-organizational cooperation. Among 96 SMEs, 29 enterprises, aside from cooperation with national organizations, also undertake international cooperation (with foreign organizations). These 29 SMEs completed a double questionnaire, i.e. in the context of both domestic and international cooperation. Therefore, 125 observations were obtained.

Most of the investigated SMEs $(91.7 \%)$ were small, whereas $8.3 \%$ of SMEs were medium sized enterprises. Regarding the age of companies, $29.2 \%$ of companies were up to 10 years old, $43.7 \%$ were between 11 and 20 years old, and $25 \%$ were over 20 years old. Taking into account the dominant activity, $51.04 \%$ of companies dealt with construction of buildings, $33.33 \%-$ specialized construction activities, and $15.63 \%$ - civil engineering.

All statistical calculations were performed using Statistica v.13 software.

\section{Measures}

A set of items related to cooperation and company performance was developed on the basis of literature review. The items were used unchanged (after being translated into Polish) or modified for research purposes.

To measure the motivation for cooperation, items were generated, based on works of Beuve \& Saussier (2011), Fernandez-Ardevol \& Masllorens (2011), and Danik \& Lewandowska (2013). From Rese \& Baier (2011), scales of trust between partners (four adapted versions of the authors' items), compatibility of the network partners, and ability of the network partners to cooperate were used. The intercompany competition scale (Zhang et al., 2010) was used to measure competition between partners. Based on work of Danik \& Lewandowska (2013), twelve barriers of cooperation were distinguished. A list of eight desired business partner attributes was developed based on work of Beuve \& Saussier (2011). From Schmoltzi \& Wallenburg (2012), scales of formalization of cooperation, mutual influence, commitment and cooperation effectiveness were used. Based on literature review (e.g. Danik \& Lewandowska, 2013), ten areas of cooperation were included in the questionnaire. In order to measure the company's performance, changes in the number of employees, sales revenue and net profitability were taken into consideration. Respondents were asked how the 
measures of company performance had changed in comparison to the previous year (in per cent).

Except for measures of company performance, areas of cooperation, motivation for cooperation and desired business partner attributes, each item was measured on a five-point Likert scale ( 1 - strongly disagree and 5 - strongly agree). Motivation for cooperation and areas of cooperation were measured on a five-point scale ( 1 - never, 5 - often), and desired business partner attributes were measured on a tenpoint scale (1 - not important, 10 - very important). A sample of the questionnaire is presented in Appendix 1.

\section{Results}

Empirical dimensions of cooperation were identified carrying out an exploratory factor analysis with Varimax rotation. The Kaiser-Meyer-Olkin index of sampling adequacy and Bartlett's test for sphericity indicated that a dataset is suitable for the factor analysis. The Kaiser's criterion was used to determine the number of factors. Finally, eight dimensions of cooperation were distinguished (see Appendix 2). Original scales for mutual influence, commitment, cooperation effectiveness, compatibility of the network partners, and ability clustered together creating one factor which was interpreted as maturity to cooperate (C1). Items from the competition factor (C6), except for one item, and formalization of cooperation factor (C7) were clustered together as in the original scales. The remaining items were loaded on the following new factors: areas of cooperation (C2), motivation for cooperation (C3), barriers of cooperation (C4), desired attributes of a business partner (C5) and openness to cooperation (C8). Alpha reliabilities for the scales ranged from 0.82 to 0.95 .
To test multicollinearity, a multiple regression analysis with dimensions of cooperation was conducted, and the variance inflation factor (VIF) was calculated. All variables had VIF values of less than the limit of 10, which indicates that multicollinearity between variables in the regression models is absent.

It was checked whether the differences occurring between the mean values of dimensions for two groups of enterprises, i.e. undertaking international cooperation and undertaking only domestic cooperation, are statistically significant. For this purpose, the Mann-Whitney U test was used for two independent groups. The results of the test show that there are statistically significant differences $(p<0.05)$ relating to four dimensions of cooperation: C2, C3, C6 and C8. Mean values of these four dimensions are higher for enterprises undertaking only domestic cooperation, as compared to enterprises undertaking international cooperation.

Correlation analysis and multiple regression analysis were used to investigate the relationships between identified dimensions of cooperation and company performance. Descriptive statistics and the correlation matrix for the variables are presented in Table 1. The highest Pearson's linear correlation coefficient is between areas of cooperation (C2) and motivation for cooperation (C3). High correlation coefficients are also between maturity to cooperate $(\mathrm{C} 1)$ and both the formalization of cooperation (C7) and openness to cooperation (C8). The correlation matrix shows that the company's performance is not significantly correlated with dimensions of cooperation, except for the change in net profitability, which is negatively correlated with barriers of cooperation. However, measures of company's performance are correlated.

Descriptive Statistics and Correlation Matrix

Table 1

\begin{tabular}{|l|c|c|c|c|c|c|c|c|c|c|c|}
\hline & C1 & C2 & C3 & C4 & C5 & C6 & C7 & C8 & SR & E & P \\
\hline C1 & 1.00 & & & & & & & & & & \\
\hline C2 & $0.22^{*}$ & 1.00 & & & & & & & & & \\
\hline C3 & $0.24^{*}$ & $0.65^{*}$ & 1.00 & & & & & & & & \\
\hline C4 & 0.12 & 0.16 & $0.38^{*}$ & 1.00 & & & & & & & \\
\hline C5 & 0.14 & 0.13 & 0.04 & -0.01 & 1.00 & & & & & & \\
\hline C6 & $0.40^{*}$ & $0.20^{*}$ & $0.46^{*}$ & $0.24^{*}$ & 0.03 & 1.00 & & & & & \\
\hline C7 & $0.37^{*}$ & $0.31^{*}$ & 0.10 & 0.11 & 0.12 & 0.09 & 1.00 & & & & \\
\hline C8 & $0.56^{*}$ & 0.16 & $0.27^{*}$ & 0.12 & -0.07 & $0.45^{*}$ & $0.31^{*}$ & 1.00 & & & \\
\hline Sales revenue & 0.12 & 0.11 & 0.07 & -0.10 & 0.11 & -0.10 & 0.06 & 0.02 & 1.00 & & \\
\hline Employment & 0.09 & 0.14 & 0.09 & -0.14 & -0.16 & -0.01 & -0.03 & 0.10 & $0.35^{*}$ & 1.00 & \\
\hline Profitability & 0.08 & 0.00 & 0.01 & $-0.21^{*}$ & 0.00 & -0.03 & -0.07 & 0.13 & $0.36^{*}$ & $0.45^{*}$ & 1.00 \\
\hline Mean & 3.48 & 1.90 & 2.22 & 2.55 & 7.43 & 2.89 & 3.56 & 3.12 & 2.52 & 0.90 & 0.71 \\
\hline SD & 0.75 & 0.78 & 0.76 & 0.70 & 1.68 & 0.81 & 1.09 & 0.96 & 10.78 & 9.01 & 3.48 \\
\hline
\end{tabular}

Note: *Correlation significant of: $p<0.05$

To test which dimensions of cooperation are related the most with the company's performance, multiple regression analyses with a backward selection method were carried out. Change in the number of employees, sales revenue and net profitability are dependent variables. Dimensions of cooperation are independent variables (Table 2). The results of the regression analysis confirm the results of the correlations analysis - change in the number of employees and sales revenue is not related to any of the examined dimensions of cooperation. As for the change in net profitability, eight regression models were obtained. The last, 8th model, only includes one significant variable, barriers of cooperation (C6), and has explanatory power of 4 per cent. Results indicate a negative relation between barriers of cooperation and change in net profitability. Multiple correlation coefficients range from 0.31 to 0.21 , which indicates a weak correlation between the change in net profitability and dimensions of cooperation. The results of the regression analysis do not support $\mathrm{H} 1$. 
Anna Michna, Roman Kmieciak, Agnieszka Czerwinska-Lubszczyk. Dimensions of Intercompany Cooperation in the...

Multiple Regression Analysis Results. Dependent Variables - Company Performance

\begin{tabular}{|c|c|c|c|c|c|c|c|c|c|c|c|c|}
\hline & \multicolumn{4}{|c|}{ Change in sales revenue } & \multicolumn{4}{|c|}{ Change in the number of employees } & \multicolumn{4}{|c|}{ Change in net profitability } \\
\hline & \multicolumn{2}{|c|}{ Initial model } & \multicolumn{2}{|c|}{ Final model } & \multicolumn{2}{|c|}{ Initial model } & \multicolumn{2}{|c|}{ Final model } & \multicolumn{2}{|c|}{ Initial model } & \multicolumn{2}{|c|}{ Final model } \\
\hline & B & $\beta$ & B & $\beta$ & B & $\beta$ & B & $\beta$ & B & $\beta$ & $\mathrm{B}$ & $\beta$ \\
\hline C1 & 2.28 & 0.14 & 1.92 & 0.12 & 2.19 & 0.16 & & & 0.45 & 0.10 & & \\
\hline $\mathrm{C} 2$ & 0.56 & 0.04 & & & 1.84 & 0.16 & & & -0.05 & -0.01 & & \\
\hline $\mathrm{C} 3$ & 1.81 & 0.13 & & & 0.62 & 0.05 & & & 0.57 & 0.13 & & \\
\hline $\mathrm{C} 4$ & -2.11 & -0.13 & & & -2.58 & -0.19 & & & $-1.24 *$ & $-0.26^{*}$ & $-1.02^{*}$ & $-0.21 *$ \\
\hline $\mathrm{C} 5$ & 0.49 & 0.08 & & & -0.95 & -0.19 & -0.81 & -0.16 & 0.01 & 0.01 & & \\
\hline C6 & -2.51 & -0.18 & & & -0.90 & -0.08 & & & -0.52 & -0.12 & & \\
\hline $\mathrm{C} 7$ & -0.11 & -0.01 & & & -1.17 & -0.14 & & & -0.38 & -0.12 & & \\
\hline $\mathrm{C} 8$ & -0.01 & 0.00 & & & 0.73 & 0.07 & & & 0.66 & 0.17 & & \\
\hline Constant & -0.91 & & -4.23 & & 6.58 & & 6.86 & & $1.87 *$ & & 3.34* & \\
\hline $\mathrm{F}$ & 0.93 & & 1.54 & & 1.55 & & 2.78 & & 1.39 & & 5.12 & \\
\hline$R$ & 0.26 & & 0.12 & & 0.33 & & 0.16 & & 0.31 & & 0.21 & \\
\hline$R^{2}$ & 0.07 & & 0.01 & & 0.11 & & 0.03 & & 0.10 & & 0.04 & \\
\hline Adjusted $R^{2}$ & 0.00 & & 0.01 & & 0.04 & & 0.02 & & 0.03 & & 0.04 & \\
\hline $\begin{array}{l}\text { Standard error } \\
\text { of the } \\
\text { estimate }\end{array}$ & 10.80 & & 10.75 & & 8.83 & & 8.93 & & 3.43 & & 3.42 & \\
\hline$n$ & 110 & & 110 & & 110 & & 110 & & 112 & & 112 & \\
\hline
\end{tabular}

Notes: $* p<0.05$

To identify the dimensions of cooperation that are the most related to company's openness to cooperation, multiple regression analyses with a backward selection method were conducted. Openness to cooperation is a dependent variable, and the rest of the dimensions are independent variables (Table 3). Five regression models were obtained. The final model includes two variables: maturity to cooperate $(\mathrm{C} 1)$ and competition between partners (C6). The final model has an explanatory power of 37 per cent. Multiple correlation coefficients range from 0.65 to 0.61 , which indicates a strong correlation between openness to cooperation and dimensions of cooperation.

Table 3

Multiple Regression Analysis Results. Dependent Variables - Openness to Cooperation

\begin{tabular}{|c|c|c|c|c|}
\hline & \multicolumn{4}{|c|}{ Openness to cooperation } \\
\hline & \multicolumn{2}{|c|}{ Initial model } & \multicolumn{2}{|c|}{ Final model } \\
\hline & B & $\beta$ & B & $\boldsymbol{\beta}$ \\
\hline $\mathrm{C} 1$ & $0.54 *$ & $0.42 *$ & $0.58^{*}$ & $0.46^{*}$ \\
\hline $\mathrm{C} 2$ & -0.12 & -0.09 & & \\
\hline $\mathrm{C} 3$ & 0.15 & 0.12 & & \\
\hline $\mathrm{C} 4$ & -0.05 & -0.04 & & \\
\hline $\mathrm{C} 5$ & $-0.08 *$ & $-0.15^{*}$ & & \\
\hline C6 & $0.28^{*}$ & $0.24 *$ & $0.31 *$ & $0.26^{*}$ \\
\hline $\mathrm{C} 7$ & $0.15^{*}$ & $0.17^{*}$ & & \\
\hline Constant & 0.53 & & 0.18 & \\
\hline $\mathrm{F}$ & 12.20 & & 36.89 & \\
\hline$R$ & 0.65 & & 0.61 & \\
\hline$R^{2}$ & 0.42 & & 0.38 & \\
\hline Adjusted $R^{2}$ & 0.39 & & 0.37 & \\
\hline Standard error of the estimate & 0.75 & & 0.76 & \\
\hline$n$ & 125 & & 125 & \\
\hline
\end{tabular}

Notes: ${ }^{*} p<0.05$

\section{Discussion and Conclusion}

This study allowed to answer three research questions and verify the stated hypothesis. First of all, this study confirms that cooperation between construction SMEs is a complex and multidimensional construct. The study allows to identify eight dimensions of cooperation. Earlier work also attempted to identify the dimensions of cooperation
(Heide \& Miner, 1992; Mahama, 2006, Brito et al., 2014); however, they did not focus on construction SMEs.

The study did not support $\mathrm{H} 1$, which predicted a positive relationship between cooperation and performance of SMEs. None of the dimensions of cooperation is positively related to company performance, but it was observed that barriers of cooperation are negatively related to profitability. Lack of positive relationship between 
cooperation and company performance is surprising, but previous empirical research also gave mixed results (Park et al., 2010; Brito et al., 2014), although research indicating positive relationships between these constructs (Fink et al., 2010; Lamprinopoulou \& Tregear, 2011; Fink \& Harms, 2012; Maldonado-Guzman et al., 2012) seems to be predominant.

There may be a few explanations for this. It should be noted, that empirical studies differ in the applied measures and characteristics of the sample. In this study, financial measures of company's performance (change in sales and net profitability) were used. Such measures are usually not readily shared by managers/owners of SMEs. Previous research has mainly focused on operational measures. Moreover, company's performance is complex and numerous factors have impact on it (March \& Sutton, 1997). Therefore, a direct, significant and positive relationship of cooperation and financial performance might be difficult to prove. The cooperation may not have a direct impact on the financial results, but rather improves other aspects of the company's operation (cost reduction, knowledge acquisition, improvement of innovation). What is more, perhaps for the construction SMEs, cooperation is not related to the improvement of financial performance, but it is something that is necessary for survival, as it allows to obtain orders or act as a subcontractor in a highly competitive market. It is worth noticing, that in the research sample, all construction enterprises undertook intercompany cooperation.

The study also indicated factors which are highly related to a company's openness to cooperation. These factors are maturity to cooperate $(\mathrm{C} 1)$ and competition between partners (C6). It is not surprising, that an SME is more ready and willing to cooperate when it shows higher level of maturity in the context of interorganizational relationships. In this study, maturity manifests itself with e.g. a higher level of commitment and trust. Moreover, maturity to cooperate means that a company is able to achieve the set goals and select appropriate partners. Competition and similarity between partners support cooperation. The company is more open to cooperate when its partner is in the same product market, has the same suppliers or a very similar product line. This can be explained by the fact that cooperation with a competitor is an opportunity to acquire knowledge from them (Zhang et al., 2010).

The results of this study complement and confirm previous research, which emphasized the important role of trust (Rese \& Baier, 2011), commitment (Schmoltzi \& Wallenburg, 2012) and intercompany cooperation (Zhang et al., 2010) in the cooperation. Although the meaning of cooperation for companies is highlighted in the literature, so far, there have been no empirical research on the relationship between intercompany cooperation and the performance of construction SMEs. Therefore, theoretical contribution of this study is the identification of dimensions of cooperation and linking them with performance of construction SMEs.

Although the result of the study has not proven positive relationships between cooperation and increase in sales, profits and employment, it does not mean that cooperation should not be undertaken. For construction SMEs, cooperation might be necessary and could decide about the company's survival. For managers in SMEs, it is useful to know what fosters and hampers intercompany cooperation. Because the higher the level of maturity to cooperate, the higher the openness to cooperate. Managers should pay particular attention to factors which shape the company's maturity, e.g. building trust relationships with partners, willingness to commit, selecting appropriate partners in terms of their compatibility and ability to cooperate. On the other hand, managers should take action to overcome barriers of cooperation, which are negatively related to profitability.

This study has some limitations that may be addressed by future research. Firstly, in this research, only three measures of the company's performance were used. Therefore, future research should examine how the cooperation in the construction industry affects nonfinancial measures of company's performance, e.g. productivity, technological innovation or customer satisfaction. Moreover, it is recommended to investigate the relationship between cooperation and its effectiveness, e.g. whether the cooperation achieved the intended goals, strengthened partners' competitive advantage or contributed to core competences. Secondly, the study is cross-sectional. However, the state of cooperation and its relationship with performance may change over time. Hence, a longitudinal study may be warranted to investigate the casual relation between cooperation and performance. Thirdly, the study was conducted among 96 Polish construction SMEs. The relatively small sample size from only one country limits the generalizability of the results. It would be interesting to conduct similar study in another country, using a larger sample size. Finally, this study has identified eight dimensions of intercompany cooperation in the construction industry. Still, it would be unreliable to claim that this list is complete. Future research may include additional factors, like knowledge exchange, shared problem solving and willingness to adapt to changes (Heide \& Miner, 1992).

\section{Appendix 1. A Sample of the Questionnaire}

\begin{tabular}{|c|c|c|c|c|c|c|c|c|c|c|}
\hline \multirow[b]{3}{*}{ 8. As part of cooperation: } & \multicolumn{10}{|c|}{ cooperation } \\
\hline & \multicolumn{5}{|c|}{ domestic } & \multicolumn{5}{|c|}{ international } \\
\hline & 1 & 2 & 3 & 4 & 5 & 1 & 2 & 3 & 4 & 5 \\
\hline a) we trust each other & & & & & & & & & & \\
\hline b) we are equal to each other & & & & & & & & & & \\
\hline c) we are willing to share knowledge & & & & & & & & & & \\
\hline d) we are open to the necessary changes & & & & & & & & & & \\
\hline 14. The organizations we cooperate with are equipped with: & 1 & 2 & 3 & 4 & 5 & 1 & 2 & 3 & 4 & 5 \\
\hline a) good communication behavior & & & & & & & & & & \\
\hline b) adequate bureaucratic structures & & & & & & & & & & \\
\hline
\end{tabular}


c) sufficient man-power resources

d) sufficient IT resources

e) sufficient financial resources

\section{Appendix 2. Dimensions of Cooperation}

C1. Maturity to cooperate $(\alpha=0.953)$

1. As part of cooperation, we trust each other.

2. The organizations with whom we cooperate have an equal say with respect to all cooperation transactions.

3. Organizations with whom we cooperate can mutually influence the other in making decisions related to the cooperation.

4. We are willing to dedicate whatever people and resources are necessary to maintain this cooperation.

5. We are willing to make long-term investment in this cooperation.

6. We are willing to make sacrifices to help our cooperation partner.

7. We are very loyal to our cooperation partner.

8. The cooperation has contributed to our core competences and strengthened our competitive advantage.

9. Overall, we are very satisfied with the performance of this cooperation.

10. The cooperation has realized the goals we set out to achieve.

11. Cooperation develops correctly with respect to goals.

12. Cooperation develops correctly with respect to financial affairs.

13. Cooperation develops correctly with respect to quality specifications.

14. Cooperation develops correctly with respect to schedules and deadlines.

15. Cooperation develops correctly with respect to performance evaluation.

16. The organizations we cooperate with are equipped with good communication behavior.

17. The organizations we cooperate with are equipped with adequate bureaucratic structures.

18. The organizations we cooperate with are equipped with sufficient man-power resources.

19. The organizations we cooperate with are equipped with sufficient financial resources.

C2. Areas of cooperation $(\alpha=0.895)$

How often do you cooperate in...

1. the production area?

2. acquiring resources?

3. the distribution area?

4. human resources?

5. research and development?

6. IT and administration?

7. finances?

8. the promotion and marketing?

9. expert opinions?

C3. Motivation for cooperation $(\alpha=0.905)$

How often is cooperation motivated by...

1. the lack of equipment?

2. a lack of competence?

3. the possibility of risk sharing between cooperating companies?

4. access to information, know-how?

5. access to technology?

6. informal contacts between managers?

7. increased flexibility?

8. improving the quality of works carried out?

9. improving shopping?

10. improving the financial situation?

11. a stronger competitive position?

12. the timely payment of financial obligations?

C4. Barriers of cooperation $(\alpha=0.886)$

We are struggling with...

1. negative cooperation experience

2. a lack of full trust

3. legal barriers

4. risk of creating new competitors

5. necessity to share profits

6. the unreliability of cooperating organizations

7. addiction from cooperating organizations

8. joint and several liability 
9. political barriers

10. administrative barriers

11. economic barriers

12. leak of information and know-how

C5. Desired attributes of a business partner $(\alpha=0.821)$

When establishing cooperation, we take into account...

1. reputation.

2. timely delivery (realization) guarantee.

3. the price.

4. label.

5. technical competence.

6. the guarantee to sign a long-term contract.

7. belonging to the same group of enterprises.

C6. Competition between partners $(\alpha=0.826)$

The organizations we work with...

1. have the same suppliers.

2. have identical key competences.

3 . are in the same product market.

4. have a very similar product line.

C7. Formalization of cooperation $(\alpha=0.839)$

1. In our cooperation, we have written agreements that spell out tasks, activities and procedures of the cooperation with a high level of detail.

2. In our cooperation we use very detailed standard operating procedures for the processes of the cooperation.

C8. Openness to cooperation $(\alpha=0.893)$

As part of the cooperation, we are...

1. equal to each other.

2. willing to share knowledge.

3. open to the necessary changes.

\section{References}

Arranz, N., \& Fdez de Arroyabe, J. C. (2008). The Choice of Partners in R\&D Cooperation: An Empirical Analysis of Spanish Firms, Technovation, 28(1/2), 88-100. https://doi.org/10.1016/j.technovation.2007.07.006

Arthur-Aidoo, B. M., Aigbavboa, C. O., \& Thwala, W. D. (2016). Attitudes of Owners which Impedes Firm's Growth: A Case of Small and Medium-sized Construction Firms in Ghana. Procedia Engineering, 164, $230-234$. https://doi.org/10.1016/j.proeng.2016.11.614

Beuve, J., \& Saussier, S. (2011). Interfirm Cooperation in Strategic Relationships: The Role of Formal Contract. Industrial and Corporate Change, 21(4), 811-836. https://doi.org/10.1093/icc/dtr059

Brito, L. A. L., Brito, E. P. Z., \& Hashiba, L. H. (2014). What Type of Cooperation with Suppliers and Customers Leads to Superior Performance? Journal of Business Research, 67(5), 952-959. https://doi.org/10.1016/j.jbusres. 2013.07.015

Cabras, I., \& Pearson, M. (2014). Innovation and Connectivity in Northern European Technical Cooperation Networks. International Journal of Innovation Management, 18(4), 1-24. https://doi.org/10.1142/S1363919614500224

Cegarra-Navarro, J. G., \& Sanchez-Polo, M. T. (2011). Influence of the Open-Mindedness Culture on Organizational Memory: An Empirical Investigation of Spanish SMEs. The International Journal of Human Resource Management, 22(1), 1-18. https://doi.org/10.1080/09585192.2011.538963

Chai, Y., \& Yang, F. (2011). Risk Control of Coopetition Relationship: An Exploratory Case Study on Social Networks "Guanxi" in a Chinese Logistics Services Cluster. The International Journal of Interdisciplinary Social Sciences, 6(3), 29-39. http://dx.doi.org/10.18848/1833-1882/CGP/v06i03/52026

Chrupala-Pniak, M., Grabowski, D., \& Sulimowska-Formowicz, M. (2017). Trust in Effective International Business Cooperation: Mediating Effect of Work Engagement. Entrepreneurial Business \& Economics Review, 5(2), 27-50. https://doi.org/10.15678/EBER.2017.050202

Danik, L., \& Lewandowska, M. (2013). Motives and Barriers in the Field of Cooperation between Companies. Research Outcomes Based on the Polish Engineering Industry. Journal of Economics and Management, 14, 21-34.

De la Maza-y-Aramburu, X., Vendrell-Herrero, F., \& Wilson, J. R. (2012). Where is the Value of Cluster Associations for SMEs? Intangible Capital, 8(2), 472-496. https://doi.org/10.3926/ic.346

Doucette, W. R., \& Wiederholdt, J. B. (1997). Cooperation in Pharmacy-Drug Wholesaler Relations. Pharmaceutical Research, 14(8), 976-983. https://doi.org/10.1023/A:1012132824121 
European Comission (2015). 2015 SBA Fact Sheet - Poland. Available from internet: http://ec.europa.eu/DocsRoom/ documents/ 16344/attachments/26/translations/en/renditions/native.

Fernandez-Ardevol, M., \& Masllorens, J. L. (2011). Determinants of Science-Based Cooperation: Evidence in a Sample of Small and Micro Firms. Managing Global Transitions, 9(4), 319-333.

Filho, A., Olave, M., \& Barreto, I. (2015). Factors that Disrupt Cooperation in Local Productive Arrangements: A Quantitative Study in the Clothing Sector in Tobias Barreto, Sergipe. Brazilian Business Review, 12(5), 16-38. https://doi.org/10.15728/bbr.2015.12.5.2

Fink, M., \& Harms, R. (2012). Contextualizing the Relationship between Self-commitment and Performance: Environmental and Behavioural Uncertainty in (Cross-Border) Alliances of SMEs. Entrepreneurship \& Regional Development, 24(3/4), 161-179. https://doi.org/10.1080/08985626.2012.670911

Fink, M., Harms, R., \& Kessler, A. (2010). The Moderating Role of Experience on the Relationship between Trust and Performance of Cooperating SMEs in Transformation Economies. Revista de Economia Mundial, 26, $135-154$. http://hdl.handle.net/10272/4869

Gulati, R., Wohlgezogen, F., \& Zhelyazkov, P. (2012). The Two Facets of Collaboration: Cooperation and Coordination in Strategic Alliances. Academy of Management Annals, 6(1), 531-583. https://doi.org/10.1080/19416520. 2012.691646

Havenvid, M. I., Holmen, E., Linne, A, \& Pedersen, A.-C. (2017). Creating Relationship Continuity across Projects in the Construction Industry: Deliberate, Emergent and Deliberately Emergent Strategies. IMP Journal, 11(2), $207-229$. https://doi.org/10.1108/IMP-07-2016-0015

Heide, J., \& Miner, A. (1992). The Shadow of the Future: Effects of Anticipated Interaction and Frequency of Contact in Buyer-Seller Cooperation. Academy of Management Journal, 35(2), 265-291. https://doi.org/10.5465/256374

Hoetoro, A. (2014). Cooperation and Competition among Clustered MSEs in East Java. Gadjah Mada International Journal of Business, 16(3), 275-293. https://doi.org/10.22146/gamaijb.5660

Holm, D. B., Eriksson, K., \& Johanson, J. (1996). Business Networks and Cooperation in International Business Relationships. Journal of International Business Studies, 27(5), 1033-1053. https://doi.org/10.1057/palgrave. jibs.8490162

Huggins, R. (1998). Local Business Co-operation and Training and Enterprise Councils: The Development of Inter-firm Networks. Regional Studies, 32(9), 813-826. https://doi.org/10.1080/00343409850117979

Kamnungwut, W., \& Guy, F. (2012). Knowledge in the Air and Cooperation among Firms: Traditions of Secrecy and the Reluctant Emergence of Specialization in the Ceramic Manufacturing District of Lampang, Thailand. Environment and Planning, 44(7), 1679-1695. https://doi.org/10.1068/a44522

Kmieciak, R., \& Michna, A. (2018). Knowledge Management Orientation, Innovativeness, and Competitive Intensity: Evidence from Polish SMEs. Knowledge Management Research \& Practice, 16(4), 559-572. https://doi.org/10.10 80/14778238.2018.1514997

Kozan, M. K., Oksoy, D., \& Ozsoy, O. (2012). Owner Sacrifice and Small Business Growth. Journal of World Business, 47(3), 409-419. https://doi.org/10.1016/j.jwb.2011.05.008

Krajnakova, E., Navikaite, A., \& Navickas, V. (2015). Paradigm Shift of Small and Medium-Sized Enterprises Competitive Advantage to Management of Customer Satisfaction. Inzinerine Ekonomika-Engineering Economics, 26(3), 327-332. http://dx.doi.org/10.5755/j01.ee.26.3.6608

Lamprinopoulou, C., \& Tregear, A. (2011). Inter-firm Relations in SME Clusters and the Link to Marketing Performance. Journal of Business and Industrial Marketing, 26(6), 421-429. https://doi.org/10.1108/08858621111156412

Lechner, C., Dowling, M., \& Welpe, I. (2006). Firm Networks and Firm Development: the Role of the Relational Mix. Journal of Business Venturing, 21(4), 514-540. https://doi.org/10.1016/j.jbusvent.2005.02.004

Lee, Y., Cho, I. \& Park, H. (2015). The Effect of Collaboration Quality on Collaboration Performance: Empirical Evidence from Manufacturing SMEs in the Republic of Korea. Total Quality Management, 2015, 26(9), 986 -1001. https://doi.org/10.1080/14783363.2015.1050169

Leick, B. (2011). Barriers to Co-Operation and Competitive Advantage: Cross-border Business Networks of Saxon and Northern Bohemian Firms. Journal for East European Management Studies, 16(2), 162-184. https://doi.org/10.5771 /0949-6181-2011-2-162

Lin, Y. H., \& Ho, S. P. (2013). Impacts of Governance Structure Strategies on the Performance of Construction Joint Ventures. Journal of Construction Engineering \& Management, 139(3), 304-311. https://doi.org/10.1061/ (ASCE)CO. 1943-7862.0000619

Lydeka, Z., \& Adomavicius, B. (2007). Cooperation among the Competitors in International Cargo Transportation Sector: Key Factors to Success. Inzinerine Ekonomika-Engineering Economics, 51(1), 80-90. 
Mahama, H. (2006). Management Control Systems, Cooperation and Performance in Strategic Supply Relationships: A Survey in the Mines. Management Accounting Research, 17(3), 315-339. https://doi.org/10.1016/j.mar.2006.03.002

Maldonado-Guzman, G., Gonzalez-Campo, C. H., \& Galvez-Albarracín, E. J. (2012). Co-operation as a Marketing Strategy in Mexico's SMEs: An Empirical Evidence. Revista de Globalizacion, Competitividad \& Gobernabilidad, 6(2), 16-28. https://doi.org/10.3232/GCG.2012.V6.N2.01

Mantena, R., \& Saha, R. L. (2012). Co-opetition between Differentiated Platforms in Two-Sided Markets. Journal of Management Information Systems, 29(2), 109-140. https://doi.org/10.2753/MIS0742-1222290205

March, J. G., \& Sutton, R. I. (1997). Crossroads-Organizational Performance as a Dependent Variable. Organization Science, 8(6), 698-706. https://doi.org/10.1287/orsc.8.6.698

Michna, A. (2018). The Mediating Role of Firm Innovativeness in the Relationship between Knowledge Sharing and Customer Satisfaction in SMEs. Inzinerine Ekonomika-Engineering Economics, 29(1), 93-103. https://doi.org/10. 5755/j01.ee.29.1.19027

Michna, A., Kmieciak, R., \& Burzynska-Ptaszek, K. (2017). Job Preferences and Expectations of Disabled People and Small and Medium-Sized Enterprises in Poland: Implications for Disabled People's Professional Development. Human Resource Development Quarterly, 28(3), 299-336. https://doi.org/10.1002/hrdq.21280

Michna, A., Kmieciak, R., \& Czerwinska-Lubszczyk, A. (2015). Interorganizational relationships and performance of SMEs in the construction sector: past research and future directions. In T. Kessel, M. Gawlitta, C. Hilbig, \& M. Walther (Eds.), Aspekte der Baubetriebeslehre in Forschung und Praxis, (pp. 129-146). Wiesbaden: Springer Gabler. https://doi.org/10.1007/978-3-658-09359-4_9

Moorman, C., Zaltman, G., \& Deshpande, R. (1992). Relationships between Providers and Users of Market Research: The Dynamics of Trust within and between Organizations. Journal of Marketing Research, 29(3), 314-328. https://doi.org/10. 2307/3172742

Murray, J. Y., \& Kotabe, M. (2005). Performance Implications of Strategic Fit between Alliance Attributes and Alliance Forms. Journal of Business Research, 58(11), 1525-1533. https://doi.org/10.1016/j.jbusres.2004.07.005

Muthusamy, S. K., \& White, M. A. (2005). Learning and Knowledge Transfer in Strategic Alliances: A Social Exchange View. Organization Studies, 26(3), 415-441. https://doi.org/10.1177/0170840605050874

Muthusamy, S. K., White, M. A., \& Carr, A. (2007). An Empirical Examination of the Role of Social Exchanges in Alliance Performance. Journal of Managerial Issues, 19(1), 53-75.

Oliver, C. (1997). The Influence of Institutional and Task Environment Relationships on Organizational Performance: The Canadian Construction Industry. Journal of Management Studies, 34(1), 99-124. https://doi.org/10.1111/14676486.00044

Organisation for Economic Co-Operation and Development (2008). Competition in the construction industry. Available from internet: http://www.oecd.org/dataoecd/32/55/41765075.pdf. https://doi.org/10.1007/978-1-349-74027-7_52

Park, Y., Shin, J., \& Kim, T. (2010). Firm Size, Age, Industrial Networking, and Growth: A Case of the Korean Manufacturing Industry. Small Business Economics, 35(2), 153-168. https://doi.org/10.1007/s11187-009-9177-7

Perry, M. L., Sengupta, S., \& Krapfel, R. (2004). Effectiveness of Horizontal Strategic Alliances in Technologically Uncertain Environments: Are Trust and Commitment Enough? Journal of Business Research, 57(9), 951-956. https://doi.org/10.1016/S0148-2963(02)00501-5

Racela, O. C., \& Thoumrungroje, A. (2014). Export market orientation, interfirm communication, interfirm cooperation and export performance. International Journal of Management and Marketing Research, 7(1), 1-14.

Raiden, A. B., \& Dainty, A. R. (2006). Human Resource Development in Construction Organisations: An Example of a "Chaordic" Learning Organisation? The Learning Organisation Journal, 13(1), 63-79. https://doi.org/10.1108/ 09696470610639130

Rese, A., \& Baier, D. (2011). Success Factors for Innovation Management in Networks of Small and Medium Enterprises. $R \& D$ Management, 41(2), 138-155. https://doi.org/10.1111/j.1467-9310.2010.00620.x

Rezgui, Y., \& Miles J. (2010). Exploring the Potential of SME Alliances in the Construction Sector. Journal of Construction Engineering and Management, 136(5), 558-567. https://doi.org/10.1061/(ASCE)CO.1943-7862. 0000150

Sarkar, M. B., Echambadi, R., Cavusgil, S. T., \& Aulakh, P. S. (2001). The Influence of Complementarity, Compatibility, and Relationship Capital on Alliance Performance. Journal of the Academy of Marketing Science, 29(4), 358-373. https://doi.org/10.1177/03079450094216

Schmoltzi, C., \& Wallenburg, C. (2012). Operational Governance in Horizontal Cooperations of Logistics Service Providers: Performance Effects and the Moderating role of Cooperation Complexity. Journal of Supply Chain Management, 48(2), 53-74. https://doi.org/10.1111/j.1745-493X.2011.03262.x 
Sengun, A. E., \& Wasti, S. N. (2011). Trust Types, Distrust, and Performance Outcomes in Small Business Relationships: The Pharmacy-Drug Warehouse Case. The Service Industries Journal, 31(1-2), 287-309. https://doi.org/10. 1080/02642060902759137

Sepehri, M., \& Fayazbakhsh, K. (2011). A Quantitative Examination of Competition, Coopetition and Cooperation in Supply Chains. South African Journal of Business Management, 42(3), 61-70. https://doi.org/10.4102/sajbm. v42i3.500

Sung-Lin, H., \& Min-Ren, Y. (2011). Contribution-Based Profit-Sharing Scheme for Joint Ventures. Technological and Economic Development of Economy, 17(3), 445-458. https://doi.org/10.3846/20294913.2011.580578

Walley, K. (2007). Coopetition: An Introduction to the Subject and an Agenda for Research. International Studies of Management and Organization, 37(2), 11-31. https://doi.org/10.2753/IMO0020-8825370201

Welling, D. T., \& Kamann, D. J. (2001). Vertical Cooperation in the Construction Industry: Size Does Matter. Journal of Supply Chain Management, 37(3), 28-33. https://doi.org/10.1111/j.1745-493X.2001.tb00110.x

Yang, J., Wang J., Wong, W. Y. C., \& Lai, K. H. (2008). Relational stability and alliance performance in supply chain. Omega, 36(4), 600-608. https://doi.org/10.1016/j.omega.2007.01.008

Yitmen, I. (2013). Organizational Cultural Intelligence: A Competitive Capability for Strategic Alliances in the International Construction Industry. Project Management Journal, 44(4), 5-25. https://doi.org/10.1002/pmj.21356

Yong Koh, T., \& Rowlinson, S. (2012). Relational Approach in Managing Construction Project Safety: A Social Capital Perspective. Accident Analysis and Prevention, 48, 134-144. https://doi.org/10.1016/j.aap.2011.03.020

Zaheer, A., McEvily, B., \& Perrone V. (1998). Does Trust Matter? Exploring the Effects of Interorganizational and Interpersonal Trust on Performance. Organization Science, 9(2), 141-159. https://doi.org/10.1287/orsc.9.2.141

Zeng, S., Xie, X., \& Tam, C. (2010). Relationship between Cooperation Networks and Innovation Performance of SMEs. Technovation, 30(3), 181-194. https://doi.org/10.1016/j.technovation.2009.08.003

Zhang, H., Shu, C., Jiang, X., \& Malter, A. (2010). Managing Knowledge for Innovation: The Role of Cooperation, Competition and Alliance Nationality. Journal of International Marketing, 18(4), 74-94. https://doi.org/10. 1509/jimk.18.4.74

The article has been reviewed.

Received in July 2018; accepted in April 2020. 